\title{
Evidence of Diminishing Marginal Product of Wetlands for Damage Mitigation
}

\author{
J. Luke Boutwell*, John V. Westra \\ Department of Agricultural Economics, Louisiana State University, Baton Rouge, USA \\ Email: ${ }^{*}$ boutw3@Isu.edu
}

Received 3 January 2015; accepted 21 January 2015; published 26 January 2015

Copyright (C) 2015 by authors and Scientific Research Publishing Inc.

This work is licensed under the Creative Commons Attribution International License (CC BY). http://creativecommons.org/licenses/by/4.0/

c) (7) Open Access

\begin{abstract}
Communities along the USA coast are highly vulnerable to coastal storms. Trends in population growth, climatic events and land use are likely to exacerbate future damages. Coastal management entities are faced with decisions about how to manage resources in a manner that improves environmental quality and provides the maximum benefit for coastal populations. This is particularly true along the USA coast of the Gulf of Mexico, where coastal storms are common, land loss is rapid and states are planning ambitious and costly coastal restoration projects. Many of these projects are intended to mitigate hurricane damages by using wetlands as storm buffers. The physical science literature shows that wetlands do provide situational protection from storm surge. However, little economic analysis has explored the effect of wetlands on economic losses. This analysis uses hurricane simulation data to estimate county- or parish-level damages based on observed damages from coastal storms making landfall along the Gulf coast. A model describing these damages as a function of wetland area, socio-economic conditions and storm intensity allows the estimation of the value of wetlands for their protective ecosystem services. This analysis finds that wetlands are valuable for storm damage mitigation and that wetland area change is most impactful where wetlands are most scarce. The implications of these finding are significant for coastal restoration decisions in a changing environment.
\end{abstract}

Keywords

Wetlands, Hurricane, Economic Damage, Storm Surge, Resilience

\section{Introduction}

Coastal communities across the world are vulnerable to damages from coastal storms. Coastal storms commonly reach intensities that enable wind, waves and storm surge to damage infrastructure, interrupt commerce and

\footnotetext{
"Corresponding author.
} 
cause loss of life. Coastal population growth, local wetland loss, sea level rise and potentially more frequent and intense coastal storms all serve to increase the susceptibility of coastal communities to economic damages. Wetland restoration and conservation programs are among the measures being used to mitigate damages from storm surge flooding. In the USA Gulf of Mexico, vast wetland resources provide protection against tropical storms and hurricanes. However, these resources are being lost at relatively rapid rates, increasing vulnerability to economic damages. Consequently, coastal management entities are taking ambitious action to reverse wetland loss.

The focus on using natural landscapes for building community resilience has intensified in recent years. After Hurricanes Katrina and Rita caused extensive damage to the Northern coast of the Gulf of Mexico, some scientists and policy makers became concerned about how wetland loss contributed the vulnerability of at-risk communities [1]. More recently, the damage caused by Hurricane Sandy along the East coast of the USA prompted a new interest in this topic. One year after the storm, Executive Order 13653 established the Federal Interagency Council on Climate Preparedness and Resilience. Among the purposes of this group is to "enhance community preparedness and resilience by utilizing and sustaining natural resources" [2]. In order to effectively utilize natural resources, including wetlands, to enhance community resilience and reduce storm impacts, it will be necessary to reach a better understanding about how natural features mitigate damages and how that mitigation is valuable.

\subsection{Wetlands as Buffers}

Wetlands attenuate wave energy though various physical processes. As waves make contact with wetlands, vegetation and underlying substrate reduce water velocity and turbulence despite friction and drag [3]. Partially submerged and emergent wetlands, such as salt marshes and intertidal forests, are most effective at reducing wave energy in this manner [4]. Wetland ecosystems also facilitate wave energy reduction by more indirect mechanisms. Because organic and rooted sediments erode less quickly than other seafloor substrates and wave height is proportional to water depth, wetland presence can result in the build-up of bathymetric conditions that can limit the damaging potential of waves [5]. Large-scale physical science models and small scale flume experiments have allowed scientists to understand the physical means by which wetlands reduce wave energy relatively well [6]-[8].

Despite the interaction between wetlands and wave energy being understood relatively well, the monetary value of wetlands for risk reduction is still poorly understood and few economic analyses exist. This should be of concern because resources are being allocated to coastal restoration projects that seek to improve the stormreadiness of coastal communities [9] [10]. If the objective is to create a sustainable and resilient coast, both economically and ecologically, managers must consider trade-offs between ecosystem services provided by different coastal restoration projects. These considerations will require comparable measures of the benefits provided and costs incurred by those who will be affected by these decisions. Because of the magnitude of damages that can result from hurricane impacts, small proportional reductions in damages can be valuable relative to other ecosystem services making the analysis of this ecosystem service particularly important for project prioritization.

\subsection{Economic Valuation}

Farber (1987) estimated the effect of the distance of wetlands over which a storm passed on economic damages from four storms in Louisiana. Distance of wetlands traversed was thought to be the appropriate construct to measure for analyzing wind damages, because wetlands might cause the winds from a storm to weaken by eliminating the warm water necessary for storms to maintain intensity. This analysis focuses on wind damage and excludes damage caused by flooding. Although this research is the first economic analysis of the value of wetlands for damage mitigation, the model used suffers from many statistical and conceptual defects and has a poor fit for the data. The estimated effect of a loss of one mile of wetlands across the entire coast of Louisiana is $\$ 1.1$ $\$ 3.7$ million (1980 USD) in increased future wind damages, or approximately $\$ 64,000$ annually. This corresponds to a per-acre value of $\$ 7$ - $\$ 23[11]$.

Wind damages represent a small proportion of total damages that result from most coastal storms [11]. Storm surge damage causes the greatest impact on residences and infrastructure. Recent advances in storm surge modeling have allowed more detailed analysis of the interaction between wetlands and water flow, and are therefore useful for describing the consequent reduction in damage [12]. Barbier et al. (2013) measured the effect of wet- 
land continuity and vegetative roughness on storm surge inundation, and estimated the consequent economic value of that effect. Results of that analysis suggest that, for a $10 \%$ increase in wetland continuity (wetland-water ratio) over approximately $6 \mathrm{~km}$ of wetlands, damages will be reduced by about $\$ 591,000-\$ 792,000$ for a storm with a maximum storm surge of 2.3 meters. Similarly, a marginal increase in vegetative roughness will reduce damages by $\$ 141,000$ - $\$ 258,000$ for the same storm [13].

Hurricane damage simulations do not predict damages well in part, because they cannot predict singular events that may greatly affect damages (e.g. the failure of a levee) [14] [15]. Additionally, analysis of observational data is the only way to infer causal relationships. Because the current state of storm measurement and damage reporting does not permit analysis at a scale that allows for the investigation of the interactions between the actual physical processes performed by wetlands and the resulting damage reduction, observational analysis is limited. However, it is still possible to measure the effect of wetlands on damages at a scale that the data permit in order to broadly estimate the value of the risk reduction provided by wetlands.

Costanza et al. (2008) estimated the value of wetlands for storm damage mitigation using this approach. Using data from 34 hurricanes along the USA East and Gulf coasts, a regression model was created that described damages as a function of wetland presence (among other variables), so that the effect of wetlands could be derived statistically. This approach is sometimes called the expected damage function approach (EDF) [16]. Wetland area and GDP were measured within a $100 \mathrm{~km}$ wide by $100 \mathrm{~km}$ inland swath around landfall for each storm, and used as variables in a regression. Results of that analysis estimated the annual per-hectare value of wetlands for states along the East and Gulf Coasts for storm protection to be approximately \$3200 (2004 USD), but this value varied drastically based on the area of wetlands and wetland proximity to at-risk populations.

The monetary value of the storm protection provided by wetlands depends on physical characteristics of the coastline, socioeconomic features of the impacted community and meteorological characteristics of the storm. Storm surge inundation varies under different local bathymetric and morphological conditions [6], which make economic analysis difficult because such spatially refined damage estimates are rarely available. Wetlands also have different influences on inundation for storms of varying intensity with wetlands having less of an effect on inundation for strong storms [5] [17] [18]. Additionally, the protection provided by wetlands is most valuable where the value of the protected buildings, assets and infrastructure is greatest. This is why the value of the protection provided by wetlands cannot be described economically based on inundation reduction alone-because it is not the reduced inundation that is valuable per se, but the damage that is avoided. Finally, the economic effect of a wetland gain or loss depends on the initial condition of the wetland. An incremental gain in wetland area may be highly valuable for storm protection where wetlands are most scarce (i.e. there is the least initial protection). Similarly, the same incremental gain in area may contribute no additional damage mitigation when the gain is made to an extensive area of wetlands that initially provides protection to the extent that wetlands can. In economics, this is known as diminishing marginal product. In this case, the damage mitigated by wetlands increases as wetlands get larger, but the rate-of-increase falls as wetlands get larger. This idea will be explored further below.

\section{Methodology}

This paper estimates the value of wetlands along the Northern Gulf of Mexico using data from 24 storms that made landfall in the region from 1995 to 2008. Following the EDF approach, a damage model is estimated using ordinary least squares (OLS) regression. This model describes damages as a function of storm intensity, wetland protection and population. In this way, the coefficient estimate for the wetland variable can be interpreted as the reduction in damages that can be expected from a unit increase in wetlands. Because the damage variable is a financial measure, the coefficient estimate for the wetland variable will be in monetary terms. This provides a reasonable lower bound estimate for the value of wetlands for risk reduction under the assumption that a community is willing to pay to keep a wetland at least as much as they stand to lose (through an increase in vulnerability) if that wetland were to be lost. The model is

$$
D=\alpha+\beta_{1} x_{1}+\beta_{2} x_{2}+\beta_{3} x_{3}+e_{i}
$$

where $D$ is the economic damages, $x_{1}$ is storm intensity measured by wind speed, $x_{2}$ is the area of wetland along the coast, $x_{3}$ is the population as a measure of economic activity, $\alpha$ is a constant term, $e_{i}$ is a residual error term and $\beta_{i}$ are the coefficient estimates for the independent variables. The coefficient of interest for the value of wetlands is $\beta_{2}$. 


\subsection{Data}

All data describe county- or parish-level characteristics for each variable. Each sample in the dataset represents the impact of a tropical storm or hurricane on a county or parish along the USA Gulf of Mexico from Matagorda County, Texas to Okaloosa County, Florida. There are a total of 201 samples in the dataset. The storm intensity variable is maximum sustained winds at the time of landfall and was obtained from the National Oceanic and Atmospheric Administration (NOAA) National Climatic Data Center (NCDC) extreme weather reports [19]. For the wetland protection variable, areal data was obtained from the US Fish and Wildlife Service (USFWS) for all estuarine wetlands as defined by [20] as..."consist(ing) of deepwater tidal habitats and adjacent tidal wetlands that are usually semi-enclosed by land but have open, partly obstructed or sporadic access to the open ocean, and in which ocean water is at least occasionally diluted by freshwater runoff from the land. The salinity may be periodically increased above that of the open ocean by evaporation. Along some low-energy coastlines there is appreciable dilution of sea water. Offshore areas with typical estuarine plants and animals, such mangroves and oysters are also included in the estuarine system".

The areal data are divided by the length (in kilometers) of coastline in each county or parish that is exposed to open water or estuary, so the variable used in the model measures wetland area in hectares per kilometer. There are two primary justifications for using this measure. First, counties or parishes that have larger coastlines will be more exposed to storm surge inundation and hurricane damage and also more likely to have a larger wetland area. If the model did not account for length of coast, the negative effect of wetlands on damages may be obscured because samples with larger wetland areas would also incur larger damages. Second, describing wetland protection in units per mile measures the distance between the estuarine edge and coastal communities more objectively that raw area. It is not our interest how wetland size effects the provision of protection necessarily, but how the width of the protective buffer mitigates damages at the county or parish scale. Finally, population data are gathered from the USA Census Bureau and used as a measure of economic vulnerability.

The damage variable was derived using reported economic damage estimates and hurricane model simulation results to estimate county- and parish-level damage estimates. Hurricane damage data obtained from the NCDC [19] provide damage estimates related to the loss of or damage to infrastructure, residential and commercial buildings, crops and other insurable assets. Typically, a single damage estimate is provided for multiple counties or parishes. To obtain estimates at a scale appropriate for this analysis, damages were attributed to counties and parishes using results from Hazus (hazards USA) model simulations. The Hazus model is a hurricane simulation model used by the US Federal Emergency Management Agency that (among other things) simulates hurricanes and storm surge inundation levels to estimate economic damages. For each storm in the dataset, county- and parish-level damages were estimated according to the expected proportion of damages incurred by each jurisdiction as described by Hazus model results acquired from the FEMA Region IV Flood Loss Atlas [21]. So, the values that compose the damage variable are the proportion of raw observed damages reported by NCDC that is expected, according the Hazus results, to be incurred by a county or parish given the characteristics of the storm and the counties and parishes involved. Unfortunately, reliable data on damages were not available for the strongest storms either because the damages were too extensive to attribute to storm surge flooding or because storms of that intensity did not make landfall during the study period.

\subsection{Subset Analysis}

The rate at which wetland systems mitigate damages varies spatially. It has been shown that larger wetlands reduce wave energy more effectively, but that wave attenuation rates decrease as wetland area increases. So, as the distance over which waves traverse wetlands increases waves decrease and the amount that each unit of distance contributed decreased as well [22]. In economics, this concept is known as "diminishing marginal productivity" and refers to principle that increasing an input (wetlands) into the production of a good or service (protection) increases production, but further increases of that input have a persistently lesser effect on production until no additional production comes from an input. Because this concept is noted in the physical sciences and the implications of this notion could have significant impacts on the economic implications of wetland gains and losses, this analysis explores whether there is evidence of similar interactions in this data.

To investigate whether wetlands mitigate damages differently according to size characteristics, the dataset was divided at the median of the wetland variable to explore the differences in the regression coefficient estimate for wetlands between the two subsets of data. Given the limited number of storms and counties or parishes 
available for analysis, there is concern that further disaggregation of the data would limit the validity of findings. However, these results could indicate where future research is needed or promising.

\section{Results}

\subsection{Model Diagnostics and Results}

Results from the OLS regression are shown in Table 1. The model has an R-squared value of 0.14 . Both the wind variable and the wetlands variable have parameters estimates that are statistically significant at greater than the 0.05 level. These measures of goodness-of-fit and explanatory power suggest that, while the damage variable is not fully explained by this model, wind and wetland protection are factors influencing the economic damage from coastal storms. Model diagnostics reveal evidence of heteroskedasticity in the dependent variable. The Breusch-Pagan test is a test of null hypothesis that error variance is equal throughout the data [23]. The large chi-squared value of $188.75(\mathrm{P}<0.001)$ for this model rejects that null hypothesis. Additionally, the heteroskedasticity is visually apparent in Figure 1.

Heteroskedasticity refers to the unequal distribution of residual errors between subsets of the data. This violates an assumption that is necessary for OLS regression to produce desirable results. Specifically, unevenly distributed errors cause OLS to give equal weight to observations that contain less explanatory power than others. For this reason, the linear combination of estimates that minimizes the sum of squared residuals is not the combinationthat minimizes variance. So, the coefficients are not the best linear unbiased estimates [24]. The use of a robust transformation of the variance-covariance estimator weights the errors in order to make them more reliable for deriving confidence intervals and tests for significance by accounting for unequal variance, but this does not change the coefficient estimates [25].

The coefficient of the wind variable is highly significant, implying that damages are sensitive to storm intensity. These results suggest that a one kilometer/hour increase in wind speed increases expected damages by approximately $\$ 3.8$ million (2010 USD). Importantly, the coefficient estimate for the wetland variable is negative and significant. This parameter indicates that, for a gain (or loss) of one hectare of wetlands per kilometer of coastline, the expected benefits (or costs) are approximately $\$ 26,410$ per storm according to this data. For a county with $100 \mathrm{~km}$ of coastline that is impacted by a tropical storm or hurricane every other year, this value is approximately $\$ 135 /$ ha annually or a net present value (NPV) of $\$ 2600$ - $\$ 3578 /$ ha (that is, the present value of future benefits provided by that wetland area over 50 years using a 3\% - 5\% discount rate).

\subsection{Subset Analysis}

The data were divided at the median of the wetland variable, $1550 \mathrm{ha} / \mathrm{km}$, to explore the evidence for decreasing marginal productivity of wetlands for damage mitigation as they increase in abundance. The first subset, subset one, includes those counties and parishes with less than the median, where wetlands are least abundant. Subset two includes those counties and parishes above the median, where wetlands are prevalent. Results for the regression analysis for subsets one and two are shown in Table 2 and Table 3 , respectively.

The value of wetlands for damage mitigation implied by the results is significantly greater for the subset with fewer wetlands than the subset with more wetlands. The results in Table 2 indicate that, for an increase of one hectare of wetlands per kilometer of coastline, the expected reduction in damages is expected to be approximately $\$ 194,000$ per storm. The corresponding results from Table 3 show that the null hypothesis that the wet-

\section{Table 1. OLS Regression Results (Full Dataset).}

\begin{tabular}{ccccc}
\hline \multirow{2}{*}{ Variable } & \multicolumn{3}{c}{ Coefficient Diagnostics } \\
\cline { 2 - 6 } & Coefficient & Standard Error & $\mathrm{t}$ & $\mathrm{P}$ \\
\hline Wind & 3774831 & 1079940 & 3.5 & 0.001 \\
Wetlands & -26409.96 & 8175.609 & -3.23 & 0.001 \\
Population & 145.4065 & 141.3755 & 1.03 & 0.305 \\
Constant & $-1.49 \mathrm{E}+08$ & $7.02 \mathrm{E}+07$ & -2.12 & 0.035 \\
\hline
\end{tabular}

Table 1 shows the coefficient estimates for the independent variables in the OLS regression along with their respective standard errors and t-statistic Observations $=201 ; \mathrm{R}^{2}=0.144$. 


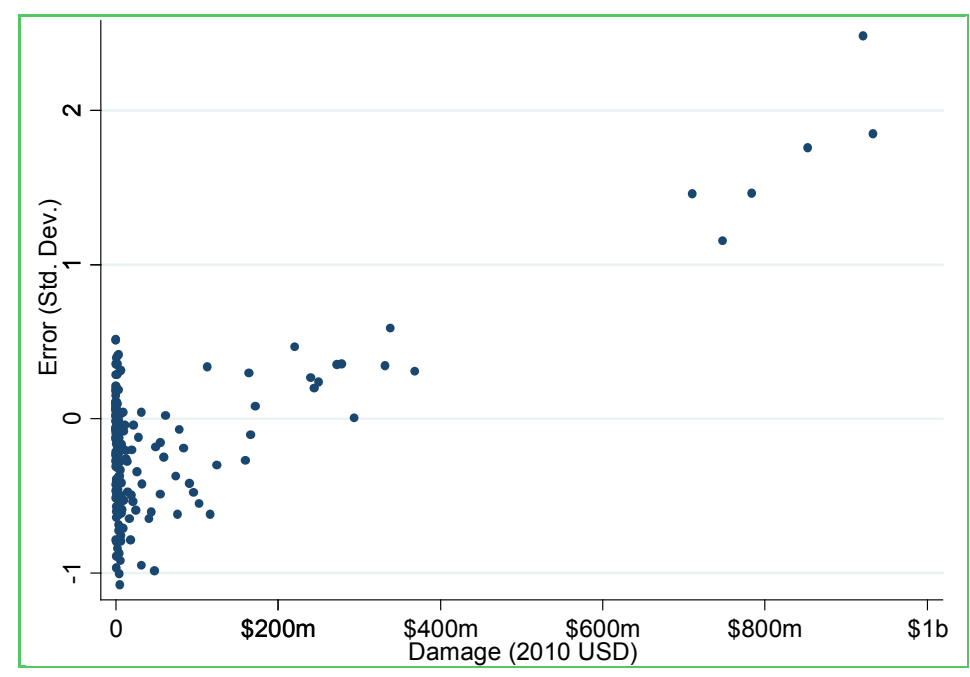

Figure 1. Scatterplot (residual variance vs. dependent variable).

Table 2. OLS regression results (subset one).

\begin{tabular}{ccccc}
\hline \multirow{2}{*}{ Variable } & & \multicolumn{3}{c}{ Coefficient Diagnostics } \\
\cline { 2 - 5 } & Coefficient & Standard Error & $\mathrm{t}$ & $\mathrm{P}$ \\
\hline Wind & 5606895 & 1757004 & 3.19 & 0.002 \\
Wetlands & -193965.7 & 71226.82 & -2.72 & 0.008 \\
Population & 157.1753 & 230.9334 & 0.68 & 0.498 \\
Constant & $-1.68 \mathrm{E}+08$ & $1.26 \mathrm{E}+08$ & -1.33 & 0.186 \\
\hline
\end{tabular}

Table 2 shows the coefficient estimates for the independent variables in the OLS regression along with their respective standard errors and t-statistic. Observations $=100 ; \mathrm{R}^{2}=0.2$.

Table 3. OLS regression results (subset two).

\begin{tabular}{ccccc}
\hline \multirow{2}{*}{ Variable } & \multicolumn{3}{c}{ Coefficient Diagnostics } \\
\cline { 2 - 5 } & Coefficient & Standard Error & $\mathrm{t}$ & $\mathrm{P}$ \\
\hline Wind & 1257673 & 590882.6 & 2.13 & 0.036 \\
Wetlands & -10286.43 & 5804.732 & -1.77 & 0.08 \\
Population & 29.00215 & 79.72953 & 0.36 & 0.717 \\
Constant & $-1.29 \mathrm{E}+07$ & $3.37 \mathrm{E}+07$ & -0.38 & 0.703 \\
\hline
\end{tabular}

Table 3 shows the coefficient estimates for the independent variables in the OLS regression along with their respective standard errors and t-statistic. Observations $=101 ; \mathrm{R}^{2}=0.073$.

land variable has no effect on coastal storm damage cannot be rejected, meaning that wetland prevalence is not associated with reduced damages for samples with areas of wetlands greater than $1550 \mathrm{ha} / \mathrm{km}$. Decreasing marginal productivity of wetlands for damage mitigation would require that the wetland coefficient estimate for the subset with fewer wetlands be greater than that with more wetlands, which we see here. It is notable that the coefficient estimate for the subset with more abundant wetlands is not statistically different from zero. This suggests that wetland ecosystems have a size-based capacity for reducing damages in an area. Further, the counties and parishes with relative wetland areas above the median may already be maximizing the use of natural wetlands for storm damage mitigation.

The value of the capital at risk of damage in a community is known to influence damages from coastal storms. Surprisingly, no evidence of this is found in this analysis for any range of the data. It is possible that population is not an effective measure of the economic risk of storm surge inundation. However, when compared to data 
measuring the value of assets susceptible to storm surge flooding at the county or parish level, the corresponding raw USA Census Bureau population estimates had a correlation greater than 0.98, suggesting that population measures economic risk well [18]. It is also possible that this dataset is fragmented, due to the limited number of storms and counties or parishes in the dataset, to the extent that the underlying effects of the variables are not clear. The relationship between socioeconomic characteristics, hurricane impacts and economic recovery remains a relationship warranting investigation. Nevertheless, this result along with the distinct differences in wetland coefficient estimates between the two subsets of data indicates the need for a more sophisticated modeling approach for evaluating economic vulnerability and valuing the risk reduction provided by wetland systems. These models should be able to describe the non-linear relationships that are evident between human and natural systems.

\section{Conclusions}

It is clear that wetlands can be valuable as infrastructure for reducing the impacts of coastal storms. However, the extent to which these ecosystems mitigate damages varies greatly across the coastal landscape. The wave attenuation provided by any parcel of wetland depends on local bathymetric conditions, extent of wetlands, vegetation type and many other factors [22]. Not only does the inundation reduction provided by wetlands vary, but also the value of that reduction varies according to the economic vulnerability within the area of flooding.

The mitigation of hurricane damages is only one service provided by wetlands. Coastal wetlands perform a number of functions that are not performed by other forms of risk reduction (e.g. flood walls, building codes, etc.). Estuaries facilitate valuable geochemical cycles, improve water quality, sequester carbon, provide scenic beauty and recreational opportunities for residents and tourists, and serve as a vital nursery to commercially and recreationally important species. Just as with storm damage mitigation, each of these benefits are provided by wetlands at different rates across the landscape, and coastal management decisions should consider the value of these benefits as well. Still, in many coastal areas storm damage mitigation may be among the most valuable services provided by wetland ecosystems.

Effective management of coastal environments will require an understanding of how the services provided by wetlands vary geographically and how that variation affects their value. Research should focus on describing these ecosystem services in terms of productivity and economic value. Understanding the dynamics of the way that natural systems provide benefits to coastal communities will be critical for ensuring that coastal management practices maximize the health and resilience of coastal populations and ecosystems. This knowledge is relatively limited and future research in this area can improve management practices. There is no single value for the economic benefits provided by any wetland. Rather, value is context dependent, and future valuations of ecosystem services should reflect the dynamic relationships among coastal communities, environments and storms.

Emphasizing the protection of wetlands and prevention of wetland loss where the provision damage mitigation is most valuable may significantly improve future economic resilience in that area. Wetland restoration projects should be integrated with other risk reduction measure, so that the functions of wetlands are complimented and excessive losses are avoided in areas of concentrated risk. Because most restoration projects are undertaken at a scale significantly smaller than the one used in this analysis, this valuation is not perfectly applicable to any single created wetland, and local scale analysis is important for project prioritization. Nevertheless, these results show that wetlands are valuable for coastal storm damage mitigation and provide an estimate of that value.

\section{Acknowledgements}

This paper benefited from conversations with Rex Caffey and Eugene Turner. This material is based upon National Needs Fellowship research supported by the National Institute of Food and Agriculture, US Department of Agriculture (USDA), under Agreement No. 2012-38420-30202.

\section{References}

[1] Day, J.W., Boesch, D.F., Clairain, E.J., Kemp, G.P., Laska, S.B., Mitsch, W.J., et al. (2007) Restoration of the Mississippi Delta: Lessons from Hurricanes Katrina and Rita. Science, 315, 1679-1684.

http://dx.doi.org/10.1126/science. 1137030 
[2] Executive Order 13653. 78 F.R. 66819 (2013)

[3] Nepf, H., Ghisalberti, M., White, B. and Murphy, E. (2007) Retention Time and Dispersion Associated with Submerged Aquatic Canopies. Water Resources Research, 43. http://dx.doi.org/10.1029/2006WR005362

[4] Neumeier, U. and Ciavola, P. (2004) Flow Resistance and Associated Sedimentary Processes in a Spartina maritima Salt-Marsh. Journal of Coastal Research, 435-447. http://dx.doi.org/10.2112/1551-5036(2004)020[0435:FRAASP]2.0.CO;2

[5] Feagin, R.A., Lozada-Bernard, S.M., Ravens, T.M., Möller, I., Yeager, K.M. and Baird, A.H. (2009) Does Vegetation Prevent Wave Erosion of Salt Marsh Edges? Proceedings of the National Academy of Sciences, 106, 10109-10113. http://dx.doi.org/10.1073/pnas.0901297106

[6] Wamsley, T.V., Cialone, M.A., Smith, J.M., Atkinson, J.H. and Rosati, J.D. (2010) The Potential of Wetlands in Reducing Storm Surge. Ocean Engineering, 37, 59-68. http://dx.doi.org/10.1016/j.oceaneng.2009.07.018

[7] Westerink, J.J., Luettich, R A., Feyen, J.C., Atkinson, J.H., Dawson, C., Roberts, H.J. and Pourtaheri, H. (2008) A Basin- to Channel-Scale Unstructured Grid Hurricane Storm Surge Model Applied to Southern Louisiana. Monthly Weather Review, 136, 833-864. http://dx.doi.org/10.1175/2007MWR1946.1

[8] Augustin, L.N., Irish, J.L. and Lynett, P. (2009) Laboratory and Numerical Studies of Wave Damping by Emergent and Near-Emergent Wetland Vegetation. Coastal Engineering, 56, 332-340. http://dx.doi.org/10.1016/j.coastaleng.2008.09.004

[9] Coastal Protection \& Restoration Authority (CPRA) of Louisiana (2012) Louisiana's Comprehensive Master Plan for a Sustainable Coast. Office of Coastal Protection and Restoration, Baton Rouge.

[10] Gulf Coast Ecosystem Recovery Task Force (2011) Gulf of Mexico Regional Ecosystem Restoration Strategy. Gulf Coast Ecosystem Recovery Task Force, Washington DC.

[11] Farber, S. (1987) The Value of Coastal Wetlands for Protection of Property against Hurricane Wind Damage. Journal of Environmental Economics and Management, 14, 143-151. http://dx.doi.org/10.1016/0095-0696(87)90012-X

[12] Barbier, E.B. (2013) Valuing Ecosystem Services for Coastal Wetland Protection and Restoration: Progress and Challenges. Resources, 2, 213-230. http://dx.doi.org/10.3390/resources2030213

[13] Barbier, E.B., Georgiou, I.Y., Enchelmeyer, B. and Reed, D.J. (2013) The Value of Wetlands in Protecting Southeast Louisiana from Hurricane Storm Surges. PLoS ONE, 8, e58715. http://dx.doi.org/10.1371/journal.pone.0058715

[14] Rose, A. (2004) Economic Principles, Issues, and Research Priorities in Hazard Loss Estimation. In: Okuyama, Y. and Chang, S.E., Eds., Modeling Spatial and Economic Impacts of Disasters, Springer-Verlag, Berlin, Heidelberg, 13-36. http://dx.doi.org/10.1007/978-3-540-24787-6 2

[15] Schneider, P.J. and Schauer, B.A. (2006) HAZUS—Its Development and Its Future. Natural Hazards Review, 7, 4044.

[16] Barbier, E.B. (2007) Valuing Ecosystem Services as Productive Inputs. Economic Policy, 22, 177-229. http://dx.doi.org/10.1111/j.1468-0327.2007.00174.x

[17] Resio, D.T. and Westerink, J.J. (2008) Hurricanes and the Physics of Surges. Physics Today, 61, 33-38. http://dx.doi.org/10.1063/1.2982120

[18] Boutwell, J. and Westra, J. (2014) Economic Risk, Tropical Storm Intensity and Coastal Wetlands: A Factor Analysis. Selected Paper Prepared for Presentation at the 2014 Southern Agricultural Economics Association (SAEA) Annual Meeting, Dallas, 1-4 February 2014.

[19] National Climatic Data Center (NCDC) Monthly Storm Data Publication. USA Department of Commerce, NOAA. http://www.ncdc.noaa.gov/IPS/sd/sd.html

[20] Cowardin, L.M., Carter, V. and Golet, F.C. (1979) Classification of Wetlands and Deepwater Habitats of the United States. FWS/OBS79/31. USDI, US Fish and Wildlife Service, Office of Biological Service, 103.

[21] Longenecker, H.E. (2011) Development and Applications of the FEMA Region IV Coastal Flood Loss Atlas. In: Solutions to Coastal Disasters 2011, ASCE, Reston, Virginia, 650-665. http://dx.doi.org/10.1061/41185(417)57

[22] Gedan, K.B., Kirwan, M.L., Wolanski, E., Barbier, E.B. and Silliman, B.R. (2011) The Present and Future Role of Coastal Wetland Vegetation in Protecting Shorelines: Answering Recent Challenges to the Paradigm. Climatic Change, 106, 7-29. http://dx.doi.org/10.1007/s10584-010-0003-7

[23] Breusch, T.S. and Pagan, A.R. (1979) A Simple Test for Heteroscedasticity and Random Coefficient Variation. Econometrica, 47, 1287-1294. http://dx.doi.org/10.2307/1911963

[24] Greene, W.H. (2003) Econometric Analysis. Pearson Education India, Delhi.

[25] Cameron, C.A. and Trivedi, P.K. (2010) Microeconometrics Using Stata. Revised Edition. Stata Press, College Station, Texas. 
Scientific Research Publishing (SCIRP) is one of the largest Open Access journal publishers. It is currently publishing more than 200 open access, online, peer-reviewed journals covering a wide range of academic disciplines. SCIRP serves the worldwide academic communities and contributes to the progress and application of science with its publication.

Other selected journals from SCIRP are listed as below. Submit your manuscript to us via either submit@scirp.org or Online Submission Portal.
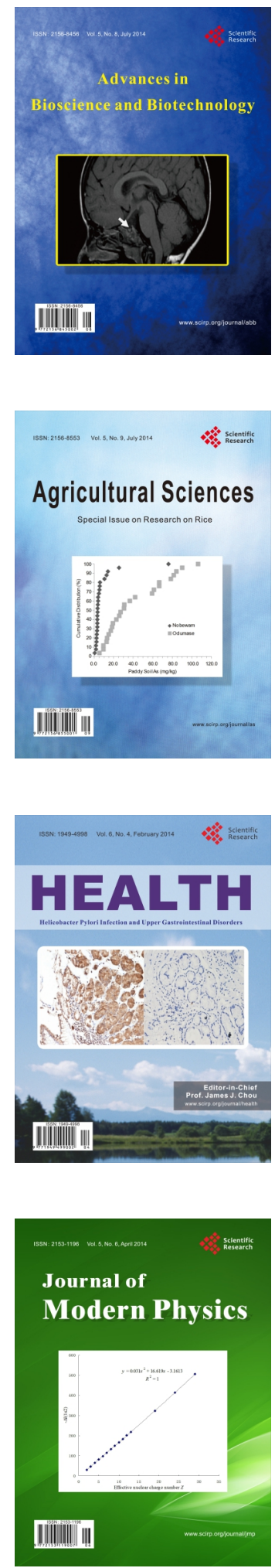
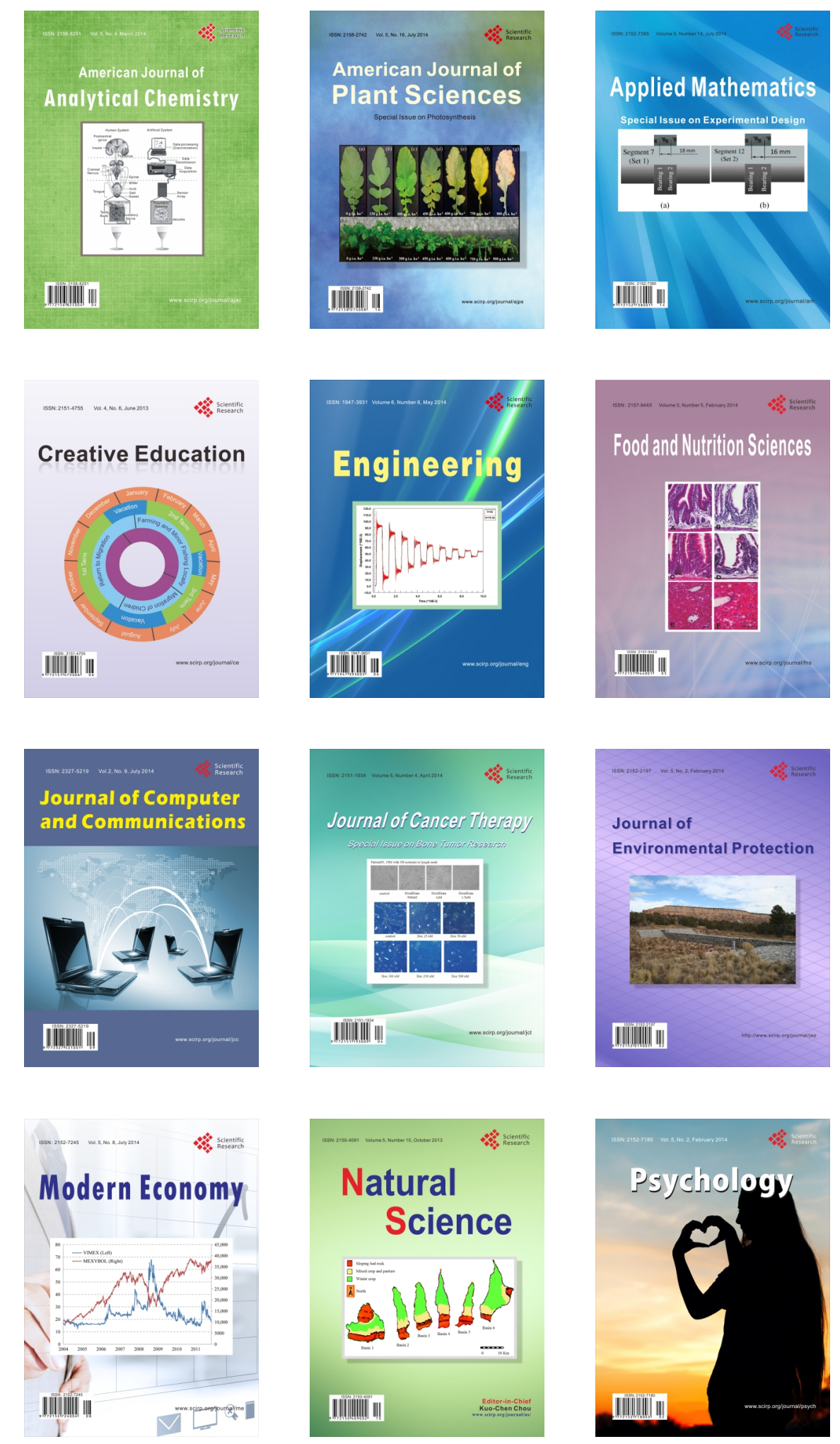